\title{
Commentary Even without our biases, the outlook for prognostication is grim
} James Downar ${ }^{1,2,3,4}$

\author{
1 University Health Network, Toronto, Ontario, Canada \\ ${ }^{2}$ Toronto East General Hospital, Toronto, Ontario, Canada \\ ${ }^{3}$ Department of Medicine, University of Toronto, Toronto, Ontario, Canada \\ ${ }^{4}$ Toronto General Hospital, 9N-926, 200 Elizabeth St, Toronto, Ontario, Canada, M5G 2C4
}

Corresponding author: James Downar, james.downar@utoronto.ca

Published: 20 July 2009

This article is online at http://ccforum.com/content/13/4/168

(c) 2009 BioMed Central Ltd

Critical Care 2009, 13:168 (doi:10.1186/cc7944)

See related research by O'Brien et al., http://ccforum.com/content/13/3/R96

\begin{abstract}
Physicians are biased and imprecise, but we are better at predicting mortality in the intensive care unit than any mathematical model currently available. But even if we were flawless prognosticators, we would still be left with the larger ethical problem of what to do with prognostic information. In order to translate prognosis into recommendation, we need to know about patient values.
\end{abstract}

\section{Physicians are biased and imprecise}

O'Brien and colleagues recently published results from the National Sepsis Practice Survey [1], in which participating physicians were given simulated clinical vignettes of patients in septic shock and asked to predict their morbidity and mortality and to make recommendations about withholding life support. Although the vignettes had an identical Acute Physiology and Chronic Health Evaluation (APACHE) II score, the investigators varied the age, body mass index and presence/absence of early-stage lung cancer of the patients in order to study the effects of these factors on the predictions and recommendations given by the participants. The investigators found that predictions of mortality and morbidity varied widely even for identical vignettes. They also found that age, high body mass index and early-stage lung cancer were all associated with a higher predicted mortality and a recommendation to limit life support despite an identical APACHE II score. Finally, they found that early-stage lung cancer was associated with a recommendation to limit life support, independent of the increase in predicted mortality.

\section{Is it wrong for us to be biased?}

Should factors such as age, body mass index and early-stage lung cancer influence our predictions of mortality? Or is physician prognostication flawed because it fails to match up with mortality rates generated by the APACHE II score? The evidence suggests that physician prognostication consistently and significantly outperforms prediction models such as the APACHE II score [2], and the latter routinely underestimate intensive care unit mortality in cancer patients [3]. Clearly, clinicians can perceive and interpret certain relevant patient factors without knowing how to include them in a mathematical model. Does this mean that a physician's assessment will always be superior to such models? Perhaps, but the observed variability in predicted mortality $(>50 \%)$ [1] should remind us that even the gold standard can be pretty imprecise.

\section{Translating a prognosis into a recommendation}

What if we could do better? What if we had the ability to measure and incorporate all relevant factors to make a perfectly accurate and precise prognosis? We would still be left with the larger ethical problem of how to translate prognostic information into a recommendation about life support. David Hume first described this as the is-ought problem [4], and he cautioned against moral systems that jump directly from a fact (something that is) to a value (something that ought to be) without a proper explanation.

To use our present example, is there a certain predicted mortality (a fact) above which we should recommend withholding life support (a value)? The medical community has so far been unable to agree on such a number [5], and many members of the public would want aggressive life support even in the face of a terrible prognosis [6,7]. Thus, even a flawless prognostic model would not by itself lead to more appropriate recommendations for our patients. There is no safety in numbers. 


\section{So how should we make recommendations?}

Beauchamp and Childress include recommendation as one of the seven key elements of informed consent [8], and the American College of Critical Care Medicine highlights the need to make recommendations about appropriate treatments for patients in the intensive care unit [9]. We cannot, however, properly recommend a course of action based solely on a prognosis. If we do so, we are imposing our own values and goals. To make the jump from is to ought, we should be using the patient's values and goals.

The importance of good communication is often repeated, but there is still much room for improvement in this area. The SUPPORT study found that fewer than $50 \%$ of physicians knew when their patients wished to forego cardiopulmonary resuscitation [10], and one-third of physicians' predictions about their patients' preferences for resuscitation were incorrect [11]. We need to do better. Good communication involves an active exploration of patient values and goals, and a frank but sensitive discussion of medical facts and options. The objective should always be to achieve a consensus among patient, family and the medical team about reasonable goals of care, and to develop a plan of care that reflects those goals.

In the study published by O'Brien and colleagues, the respondents recommended significant limitations in life support in only $2 \%$ of cases [1]. But we cannot decide whether this number is too high, too low, or perfectly appropriate because the respondents were not given any information about the values and goals of the patients in each vignette. Similarly, we cannot interpret the association between early-stage lung cancer and a recommendation to limit life support, except to say that we should not be making such recommendations solely on the basis of our own values.

\section{Conclusion}

While subjective physician assessment remains the most accurate prognostic tool available, O'Brien and colleagues have demonstrated that it can be imprecise and biased. We need to recognize the limitations of our prognostication, and need to be careful not to impose our own values when making the jump from is to ought. Only through good communication can we learn the patient's goals and values that enable us to properly translate prognosis into recommendation.

\section{Competing interests}

The author declares that they have no competing interests.

\section{Acknowledgement}

The author would like to thank Dr Jonathan Downar for his help in critically revising this manuscript.

\section{References}

1. O'Brien JM, Aberegg SK, Ali NA, Diette GB, Lemeshow S: Results from the National Sepsis Practice Survey: predictions about mortality and morbidity and recommendations for limitation of care orders. Crit Care 2009, 13:R96.

2. Sinuff T, Adhikari NK, Cook DJ, Schunemann HJ, Griffith LE, Rocker G, Walter SD: Mortality predictions in the intensive care unit: comparing physicians with scoring systems. Crit Care Med 2006, 34:878-885.

3. den Boer S, de Keizer NF, de Jonge E: Performance of prognostic models in critically ill cancer patients - a review. Crit Care 2005, 9:R458-R463.

4. Hume D: Of virtue and vice in general. In $A$ Treatise of Human Nature. Section 1, Part 1, Book 3. 1739/40.

5. Helft PR, Siegler M, Lantos J: The rise and fall of the futility movement. N Engl J Med 2000, 343:293-296.

6. Danis M, Patrick DL, Southerland LI, Green ML: Patients' and families' preferences for medical intensive care. JAMA 1988, 260:797-802.

7. Lloyd CB, Nietert PJ, Silvestri GA: Intensive care decision making in the seriously ill and elderly. Crit Care Med 2004, 32: 649-654.

8. Beauchamp TL, Childress JF. Principles of Biomedical Ethics. 6th edition. New York: Oxford University Press; 2009.

9. Truog RD, Campbell ML, Curtis JR, Haas CE, Luce JM, Rubenfeld GD, Rushton CH, Kaufman DC: Recommendations for endoflife care in the intensive care unit: a consensus statement by the American College [corrected] of Critical Care Medicine. Crit Care Med 2008, 36:953-963.

10. Anonymous: A controlled trial to improve care for seriously ill hospitalized patients. The study to understand prognoses and preferences for outcomes and risks of treatments (SUPPORT). The SUPPORT Principal Investigators. JAMA 1995, 274:1591-1598.

11. Teno JM, Hakim RB, Knaus WA, Wenger NS, Phillips RS, Wu AW, Layde P, Connors AF Jr, Dawson NV, Lynn J: Preferences for cardiopulmonary resuscitation: physician-patient agreement and hospital resource use. The SUPPORT Investigators. $J$ Gen Intern Med 1995, 10:179-186. 